\title{
Study on bacteriological profile and antibiotic susceptibility pattern in patients with diabetic foot ulcers in a tertiary care teaching hospital
}

\author{
Javedh Shareef, Sandra Sunny ${ }^{1}$, K. R. Bhagavan ${ }^{2}$ \\ Assistant Professor, Department of Pharmacy Practice NGSM Institute of Pharmaceutical Sciences, Deralakatte, \\ ${ }^{1}$ Post Graduate Student M. Pharm (Pharmacy Practice) NGSM Institute of Pharmaceutical Sciences, Deralakatte, \\ ${ }^{2}$ Professor and Head, Department of General Surgery K. S. Hegde Hospital, Deralakatte, Mangalore, Karnataka, India
}

\begin{abstract}
Introduction: Diabetic foot ulcer and infections are one of the major complications in diabetic patients leading to frequent hospitalization and increased mortality. Knowledge about the microbes that cause infections will be helpful for providing appropriate antimicrobial therapy.

Aim: To evaluate the bacteriological profile of patients with diabetic foot ulcers and their antibiotic susceptibility pattern.

Methodology: A cross-sectional study was carried out for a period of eight months in the Department of surgery in patients with diabetic foot ulcer at a tertiary care teaching hospital. Patient data relevant to the study were collected using a standard data collection form designed as per the need of the study. Details of the organisms isolated and susceptibility pattern were collected from microbiology department.

Results: A total of 122 pathogens were identified from 71 patients with male (63.38\%) predominance over females (36.61\%). Out of the 71 patients, 38 (53.52\%) patients had monomicrobial infections and 33 (46.47\%) patients had polymicrobial infections. Of the total 122 organisms, 79(64.75\%) organisms were found to be gram negative organisms and $43(35.24 \%)$ were gram positive. Pseudomonas aeruginosa found in $22(18.03 \%)$ patients was the predominant pathogen isolated followed by Klebsiella pneumonia found in $18(14.75 \%)$ patients. The gram-positive organisms isolated showed maximum susceptibility towards antibiotics Teicoplanin and Linezolid while the gram-negative organisms showed susceptibility to Imipenem, Meropenem, and Piperacillin/Tazobactum combination.

Conclusion: The study showed a preponderance of gram-negative bacilli among the isolates from the diabetic foot ulcers. It is recommended that antimicrobial sensitivity testing is necessary for initiating appropriate antibiotic regimen which will help to reduce the drug resistance and minimize the healthcare costs.
\end{abstract}

Keywords: Diabetic foot ulcer, antibiotic susceptibility, bacterial isolates

Address for correspondence: Dr. Javedh Shareef, Assistant Professor, Department of Pharmacy Practice NGSM Institute of Pharmaceutical Sciences, Deralakatte, Mangalore, Karnataka, India.

E-mail: javedh.shareef@gmail.com

Received: 22.8.2017, Accepted: 2.12.2017

\begin{tabular}{|l|l|}
\hline \multicolumn{2}{|c|}{ Access this article online } \\
\hline Quick Response Code: & Website: \\
\hline & www.joshd.net \\
\cline { 2 - 3 } & DOI: \\
& 10.4103/joshd.J_Soc_Health_ \\
\hline Diabetes_30_17
\end{tabular}

This is an open access journal, and articles are distributed under the terms of the Creative Commons Attribution-NonCommercial-ShareAlike 4.0 License, which allows others to remix, tweak, and build upon the work non-commercially, as long as appropriate credit is given and the new creations are licensed under the identical terms.

For reprints contact: reprints@medknow.com

How to cite this article: Shareef J, Sunny S, Bhagavan KR. Study on bacteriological profile and antibiotic susceptibility pattern in patients with diabetic foot ulcers in a tertiary care teaching hospital. J Soc Health Diabetes 2018;6:40-7. 
Diabetes mellitus (DM) is one of the leading prevalent chronic diseases affecting a large number of population and also a major public health problem increasing globally at an alarming rate over the past couple of decades. ${ }^{[1]}$

Long-term uncontrolled blood glucose will lead to microvascular and macrovascular complications such as ischemic heart disease, nephropathy, retinopathy, neuropathy, and no-healing ulcers (diabetic foot ulcer). ${ }^{[2]}$ Foot infections account for $20 \%$ of hospitalization of patients with DM annually. Infection worsens the wound infection, delays the healing mechanism and if interventions are not taken in time, it can progress to systemic infection, septicemia, amputation or even death. The vital components involved in treating diabetic foot infections are blood sugar control, treating co-morbidities, broad-spectrum antibiotic therapy, surgical treatment, proper dressing and wound care, personal hygiene, and prevention of recurrence. ${ }^{[3,4]}$

The selection of appropriate antibiotic regimen has become the need of the hour for the proper management of diabetic foot ulcers. Adequate knowledge about the microbes that cause infection is very important and helps in determining appropriate antibiotic therapy and proper management of these infections. Hence, the study was carried out to evaluate the microbiological characteristics of diabetic foot ulcers and their susceptibility pattern to various antimicrobials.

\section{METHODOLOGY}

This was a cross-sectional study carried out in the Department of Surgery of a tertiary care teaching hospital for a period of eight months from August 2016 to March 2017. The study was approved by the Institutional Research and Ethics Committee. All the hospitalized patients of either gender aged 18 years and above, diagnosed with diabetic foot ulcer were included in the study and patients attending the outpatient clinic as well as patients whose foot is at risk but do not have diabetic foot ulcer complications were excluded from the study. Patient case sheets of the eligible subjects who met the study criteria were reviewed by the pharmacist and their data were collected using standard data collection form designed as per the need of the study. The clinical history of the patient was elicited with regards to the age of the patient, duration of diabetes, the type of treatment which was received, the presence of other systemic illnesses, size of ulcer, and duration of the ulcer. The bacterial culture reports of patient's pus samples were obtained from laboratory investigation data of the patient. Subsequently, the antimicrobial susceptibility test was performed as per the Clinical and Laboratory Standards Institute guidelines. The microbial isolates from the samples and their susceptibility to different antimicrobials were analyzed and tabulated. Once the antibiotic susceptibility pattern was studied, the drug therapy was reviewed for their appropriateness by assessing the choice of the drug, their dosage, frequency, side effects and safety according to patients' co-morbid conditions. Data were represented as mean \pm SD, frequency, and percentage and were analyzed using SPSS (Version 16.0).

\section{Antibiotic sensitivity testing}

Antibiotic susceptibility testing was performed using the Kirby-Bauer disk diffusion method according to the clinical and laboratory standards institute (CLSI) guidelines. The antibiotic tested for gram positive bacteria were benzyl penicillin (10 units/disc), gentamicin (120 mcg/disc), ciprofloxacin (5 mcg/disc), levofloxacin ( $5 \mathrm{mcg} / \mathrm{disc})$, linezolid ( $30 \mathrm{mcg} / \mathrm{disc}$ ), tigecycline (15 mcg/disc), vancomycin (30 mcg/disc), tetracycline (30 mcg/disc), trimethoprim/sulfamethoxazole (25 mcg/isc), piperacilli/tazobactam (100/10 mcg), imipenem $10 \mathrm{mcg} / \mathrm{disc})$, meropenem $(10 \mathrm{mcg} / \mathrm{disc})$, ertapenam $(10 \mathrm{mcg} / \mathrm{disc})$, while the antibiotics tested for gram-negative bacteria were ampicillin $(10 \mathrm{mcg})$, amoxicillin/clavulanic acid (30 mcg/disc), cefuroxime (30 mc/disc), gentamicin $(120 \mathrm{mcg} / \mathrm{disc})$, ciprofloxacin (5 mcg/disc), cefoperazone/sulbactam $(75+30 \mathrm{mcg})$, amikacin $(30 \mathrm{mcg} / \mathrm{disc})$, meropenem $(10 \mathrm{mcg} / \mathrm{disc})$, doripenem $(10 \mathrm{mcg} / \mathrm{disc})$, ticarcillin/clavulanic acid $(100+10 \mathrm{mcg})$.

\section{RESULTS}

Age and gender-wise distribution of the study subjects A total number of 100 patients with diabetic foot ulcer cases were reviewed during the study period and 71 patients who met the study criteria completed the study. During the study period, males [45 $(63.38 \%)]$ predominance was noted over females [26 (36.61\%)]. The mean age of the study populations was found to be 58.78 years \pm 10.09 S.D (range: $33-85$ years). According to the age wise distribution of the study subjects, the majority of the patients (28 patients) belonged to the age group of 60-69 years followed by 19 patients in the age group of 50-59 years. The age and gender-wise distribution of the study subjects is shown in the following Table 1.

Co-morbidities among the study populations

Considering the co-morbidities in the study populations, a total of 92 co-morbidities were identified from 71 patients. 
Table 1: Age and gender-wise distribution of the study subjects

\begin{tabular}{llcr}
\hline Sl.no & Characteristics & Frequency & Percentage \\
\hline $\mathbf{1}$ & Gender & & \\
& Male & 45 & 63.38 \\
& Female & 26 & 36.61 \\
$\mathbf{2}$ & Age-wise distribution & & \\
& $30-39$ & 2 & 2.82 \\
& $40-49$ & 13 & 18.30 \\
& $50-59$ & 19 & 26.76 \\
& $60-69$ & 28 & 39.43 \\
& $70-79$ & 8 & 11.26 \\
& $\geq 80$ & 1 & 1.40 \\
\hline
\end{tabular}

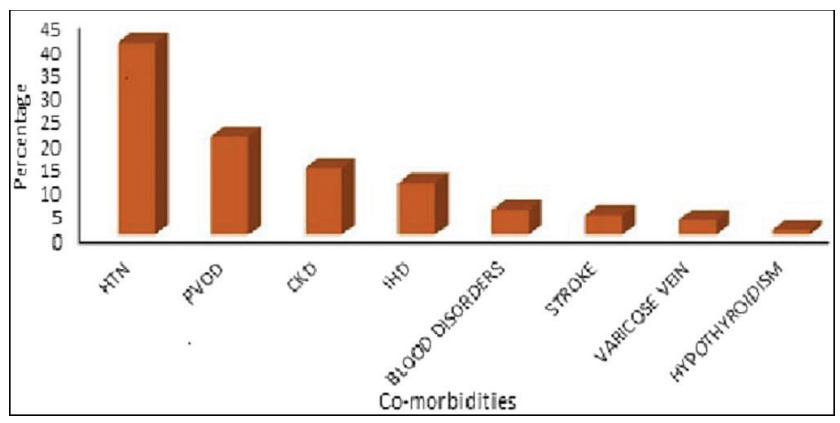

Figure 1: Pattern of co-morbidity among patients with diabetic foot ulcer

Hypertension was the most common co-morbidity identified during the study in $37(40.21 \%)$ patients followed by peripheral vascular occlusive disease $19(20.65 \%)$ and kidney diseases 13 (14.13\%). The mean duration of DM in subjects was found to be $9.24 \pm 6.778$ S.D. years (range: 0.5-32 years). It is well known that long-term uncontrolled blood glucose levels lead to macrovascular or microvascular complications including diabetic infections. In this study, the mean glycated hemoglobin value was found to be $9 \% \pm 1.894$ S.D. (range: $5-13 \%$ ), which suggests poor blood sugar control. The co-morbidities of the study populations were shown in the following Figure 1.

Distribution of subjects according to their ulcer size, severity pattern and ulcer recurrence

Among the total study populations, $43(60.56 \%)$ patients were found to develop foot ulcers of size less than or equal to $4 \mathrm{~cm}$ and $28(39.43 \%)$ subjects had ulcers greater than $4 \mathrm{~cm}$. Out of 71 patients, $26(36.61 \%)$ subjects developed necrotic lesion while $45(63.38 \%)$ had non-necrotic lesion. Among the study subjects, 8 were diagnosed with gangrene, 2 with osteomyelitis and 5 cases of abscess and cellulitis. Ulcer recurrence was observed in $23(32.39 \%)$ patients. The distribution of subjects according to their ulcer size, severity pattern, and ulcer recurrence is shown in the following Table 2 .

\section{Distribution of bacteria isolated from diabetic foot ullcers}

In this study, monomicrobial growth was seen predominantly in $38(53.52 \%)$ while $33(46.47 \%)$ subjects developed
Table 2: Size, frequency, and recurrence of ulcer in study subjects

\begin{tabular}{llc}
\hline Sl.no & \multicolumn{1}{c}{ Size } & Frequency \& Percentage \\
\hline 1 & Less than or equal to $4 \mathrm{~cm}^{2}$ & $43(60.56)$ \\
& Greater than $4 \mathrm{~cm}^{2}$ & $28(39.43)$ \\
2 & Number of patients & Frequency \\
& Recurrence present & $23(32.39)$ \\
& No recurrence & $48(67.60)$ \\
3 & Severity pattern & Frequency \\
& Non - necrotic & $45(63.38)$ \\
& Necrotic & $26(36.61)$ \\
\hline
\end{tabular}

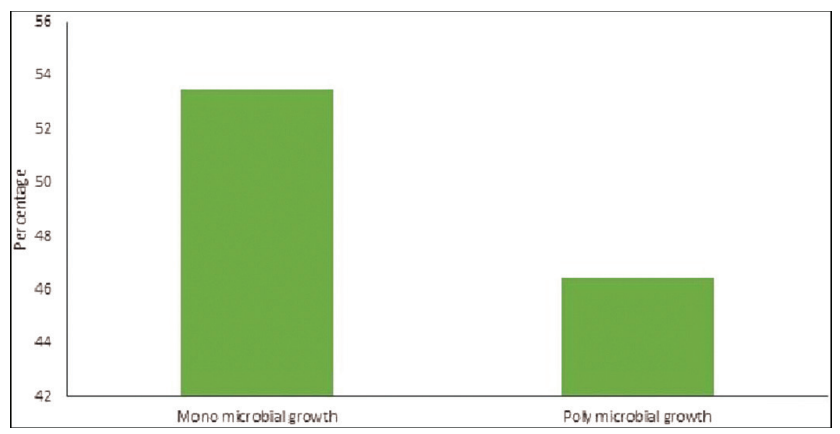

Figure 2: Nature of microbial growth in patient with diabetic foot ulcer

Table 3: Bacteria isolated from the diabetic foot ulcer of the study subjects

\begin{tabular}{|c|c|c|c|}
\hline SI no & Bacteria & $\begin{array}{c}\text { Frequency } \\
(n=122)\end{array}$ & Percentag \\
\hline \multirow[t]{5}{*}{1} & Gram-positive organisms & & \\
\hline & Coagulase negative S.aureus & 15 & 12.29 \\
\hline & Staphylococcus aureus & 15 & 12.29 \\
\hline & Enterococcus spp. & 13 & 10.65 \\
\hline & Total & 43 & 35.24 \\
\hline \multirow[t]{9}{*}{2} & Gram-negative organisms & & \\
\hline & Acinetobacter baumannii & 10 & 8.19 \\
\hline & Pseudomonas aeruginosa & 22 & 18.03 \\
\hline & Klebsiella pneumonia & 18 & 14.75 \\
\hline & E.coli & 12 & 9.83 \\
\hline & Citrobacter koseri & 2 & 1.63 \\
\hline & Proteus spp & 12 & 9.83 \\
\hline & Morganella morganii & 3 & 2.45 \\
\hline & Total & 79 & 64.75 \\
\hline
\end{tabular}

polymicrobial growth. The nature of microbial growth in diabetic foot ulcers is shown in Figure 2.

Bacteria isolated from DFUs of the study subjects

Microbiological evaluation of the ulcers revealed that the prevalence of gram-negative organisms 79 (64.75\%) were found to be more than gram-positive organisms $43(35.24 \%)$. A total of 122 organisms were isolated from 71 subjects with an average of 1.71 organisms per patient. Pseudomonas aeruginosa was the most frequent pathogen isolated from $22(18.03 \%)$ subjects followed by Klebsiella pneumoniae isolated from 18 (14.75\%) subjects. The different types of gram negative and gram positive bacteria isolated from diabetic foot ulcers are summarized in Table 3. 
Prevalence of gram positive and gram-negative bacteria Considering the bacterial growth in patients with a diabetic foot ulcer, it was found that majority of the bacterial growth were gram-negative organisms $79(64.75 \%)$ followed by $43(35.24 \%)$ gram positive. The prevalence of bacterial growth in patients with diabetic foot ulcer is shown in the following Figure 3.

Antibiotic susceptibility pattern of gram positive and gram-negative organisms

The common antibiotics are tested to determine the sensitivity pattern of the organism isolated. In this study, Enterococcus species shows maximum sensitivity to Linezolid (69.23\%) followed by Teicoplanin (61.53\%) and Benzyl Penicillin (61.53\%). Maximum susceptibility of coagulase negative Staphylococcus aureus was observed to be towards Vancomycin (73.34\%), Teicoplanin (73.34\%), and

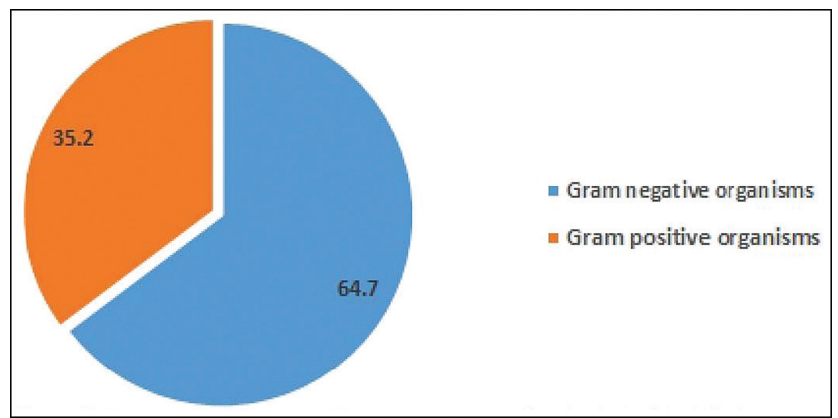

Figure 3: Prevalence of gram positive and gram negative bacteria identified from the bacterial isolates of patients with diabetic foot ulcer
Linezolid (73.34\%). Staphylococcus aureus was found to be susceptible to Vancomycin (86.67\%), Teicoplanin (86.67\%), and Linezolid (86.67\%). The maximum susceptibility of Staphylococcus was towards Tetracycline (93.34\%).

Among gram-negative organisms, Acinetobacter baumanii was found to be more susceptible to antibiotics like Tigecycline, Trimethoprim/Sulfamethoxazole and Cefoperazone/Sulbactum with $70 \%$ sensitivity each. In the case of Klebsiella species, maximum sensitivity was found towards Imipenem (77.78\%) and Meropenem (77.78\%). Proteus species showed 100\% sensitivity towards Piperacillin/Tazobactum combination while E.coli shows 100\% susceptibility towards Amikacin. Morganella species showed sensitivity towards almost all the antibiotics.

Therefore, it can be summarized that the gram-positive organisms isolated were most commonly sensitive to antibiotics Teicoplanin and Linezolid while the gram-negative organisms isolated were found to be sensitive to anitbiotics like Imipenem, Meropenem, and Piperacillin/Tazobactum combination. Table 4 and 5 show antibiotic susceptibility pattern of the organisms isolated.

The resistance pattern of the pathogens isolated in patients with diabetic foot ulcers towards the common antibiotics is highlighted in Table 6 and 7.

Table 4: Antibiotic susceptibility pattern of gram-positive organisms

\begin{tabular}{|c|c|c|c|}
\hline Antibiotics & Enterococcus spp $(n=13)$ & Coagulase negative S.aureus $(n=15)$ & Staphylococcus aureus $(n=15)$ \\
\hline Benzyl Penicillin (10 units/disc) & $8(61.53 \%)$ & $1(6.67 \%)$ & $2(13.34 \%)$ \\
\hline Penicillin (10 units/disc) & - & $1(6.67 \%)$ & - \\
\hline Gentamicin (120 mcg/disc) & $6(46.15 \%)$ & $8(53.34 \%)$ & $12(80 \%)$ \\
\hline Ciprofloxacin (5 mcg/disc) & $6(46.15 \%)$ & $4(26.67 \%)$ & $3(20 \%)$ \\
\hline Levofloxacin (5 mcg/disc) & $4(30.76 \%)$ & $4(26.67 \%)$ & 11 (73.34\%) \\
\hline Erythromycin (15 mcg/disc) & $5(38.46 \%)$ & $5(33.34 \%)$ & $5(33.34 \%)$ \\
\hline Clindamycin (2 mcg/disc) & - & $5(33.34 \%)$ & $9(60 \%)$ \\
\hline Teicoplanin (30 mcg/disc) & $8(61.53 \%)$ & $11(73.34 \%)$ & $13(86.67 \%)$ \\
\hline Linezolid (30 mcg/disc) & $9(69.23 \%)$ & 11 (73.34\%) & $13(86.67 \%)$ \\
\hline Tigecycline (15 mcg/disc) & $7(53.84 \%)$ & $5(33.34 \%)$ & $13(86.67 \%)$ \\
\hline Vancomycin (30 mcg/disc) & 7 (53.84\%) & $11(73.34 \%)$ & $13(86.67 \%)$ \\
\hline Tetracycline (30 mcg/disc) & $2(15.38 \%)$ & $8(53.34 \%)$ & 14 (93.34\%) \\
\hline $\begin{array}{l}\text { Trimethoprim-Sulfamethoxazole } \\
\text { (25 mcg/disc) }\end{array}$ & $2(15.38 \%)$ & $7(46.67 \%)$ & 7 (46.67\%) \\
\hline Piperacillin-Tazobactum (100/10 mcg) & $2(15.38 \%)$ & - & - \\
\hline Cefuroxime (30 mcg/disc) & $1(7.69 \%)$ & - & - \\
\hline Cefuroxime axetil (30 mcg/disc) & $1(7.69 \%)$ & - & - \\
\hline Cefoperazone-sulbactam (75 + 30 mcg) & $2(15.38 \%)$ & - & - \\
\hline Cefepime (30 mcg/disc) & $2(15.38 \%)$ & - & - \\
\hline Imipenem (10 mcg/disc) & $1(7.69 \%)$ & - & - \\
\hline Meropenem (10 mcg/disc) & $2(15.38 \%)$ & - & - \\
\hline Amikacin $(30 \mathrm{mcg} /$ disc) & $3(23.07 \%)$ & - & - \\
\hline Colistin (10 mcg/disc) & $2(15.38 \%)$ & - & - \\
\hline Ceftriaxone (30 mcg/disc) & $2(15.38 \%)$ & $1(6.67 \%)$ & - \\
\hline Ertapenem (10 mcg/disc) & $2(15.38 \%)$ & - & - \\
\hline Oxacillin (1 mcg/disc) & - & $2(13.34 \%)$ & $8(53.34 \%)$ \\
\hline
\end{tabular}


Table 5: Antibiotic susceptibility pattern of gram-negative organisms

\begin{tabular}{|c|c|c|c|c|c|c|c|}
\hline Antibiotics & $\begin{array}{l}\text { A.baumanni } \\
\quad(n=10)\end{array}$ & $\begin{array}{l}\text { Klebsiella } \\
\text { Species } \\
(n=18)\end{array}$ & $\begin{array}{l}\text { P.aeruginosa } \\
\quad(n=22)\end{array}$ & $\begin{array}{c}\text { E.coli } \\
(n=12)\end{array}$ & $\begin{array}{c}\text { C.koseri } \\
(n=2)\end{array}$ & $\begin{array}{l}\text { Proteus spp } \\
\quad(n=12)\end{array}$ & $\begin{array}{l}\text { Morganella } \\
\operatorname{spp}(n=3)\end{array}$ \\
\hline Gentamicin (120 mcg/disc) & $6(60 \%)$ & $10(55.56 \%)$ & $13(59.09 \%)$ & $11(91.67 \%)$ & $2(100 \%)$ & $8(66.67 \%)$ & $3(100 \%)$ \\
\hline Ciprofloxacin (5 mcg/disc) & $6(60 \%)$ & $10(55.56 \%)$ & $11(50 \%)$ & $6(27.27 \%)$ & - & $6(50 \%)$ & $2(66.6 \%)$ \\
\hline Levofloxacin (5 mcg/disc) & $5(50 \%)$ & - & $10(45.45 \%)$ & - & - & - & $1(33.3 \%)$ \\
\hline Tigecycline (15 mcg/disc) & $7(70 \%)$ & $8(44.45 \%)$ & $4(18.18 \%)$ & $4(18.18 \%)$ & $2(100 \%)$ & $1(8.33 \%)$ & - \\
\hline $\begin{array}{l}\text { Trimethoprim/Sulfamethoxazole } \\
\text { ( } 25 \mathrm{mcg} / \text { disc) }\end{array}$ & $7(70 \%)$ & $6(33.34 \%)$ & $1(4.54 \%)$ & $9(40.90 \%)$ & $1(50 \%)$ & $6(50 \%)$ & $3(100 \%)$ \\
\hline Ampicillin (10 mcg) & - & - & - & $1(8.33 \%)$ & - & $6(50 \%)$ & - \\
\hline Amoxicillin-Clavulanic acid (30 mcg/disc) & - & $9(50 \%)$ & - & - & $1(50 \%)$ & - & - \\
\hline Piperacillin-Tazobactum (100 + 10 mcg) & $6(60 \%)$ & $11(61.12 \%)$ & $8(36.36 \%)$ & $10(83.34 \%)$ & $1(50 \%)$ & $12(100 \%)$ & $3(100 \%)$ \\
\hline Cefuroxime $(30 \mathrm{mcg} / \mathrm{disc})$ & - & $5(27.78 \%)$ & - & $3(25 \%)$ & - & 9 (75\%) & - \\
\hline Cefuroxime axetil (30 mcg/disc) & - & $5(27.78 \%)$ & - & $3(25 \%)$ & - & $9(75 \%)$ & - \\
\hline Cefepime (30 mcg) & $5(50 \%)$ & $11(61.12 \%)$ & $14(63.63 \%)$ & $9(75 \%)$ & $2(100 \%)$ & $10(83.34 \%)$ & $3(100 \%)$ \\
\hline Cefoperazone-sulbactam $(75+30 \mathrm{mcg})$ & $7(70 \%)$ & $11(61.12 \%)$ & $13(59.09 \%)$ & $11(91.66 \%)$ & $2(100 \%)$ & $11(91.67 \%)$ & $3(100 \%)$ \\
\hline Imipenem (10 mcg/disc) & $6(60 \%)$ & $14(77.78 \%)$ & $19(86.36 \%)$ & $11(91.66 \%)$ & $2(100 \%)$ & - & - \\
\hline Meropenem (10 mcg/disc) & $6(60 \%)$ & $14(77.78 \%)$ & $17(77.27 \%)$ & $11(91.66 \%)$ & $2(100 \%)$ & $11(91.67 \%)$ & $3(100 \%)$ \\
\hline Amikacin $(30 \mathrm{mcg} / \mathrm{disc})$ & $6(60 \%)$ & $15(83.34 \%)$ & $16(72.72 \%)$ & $12(100 \%)$ & $2(100 \%)$ & $10(83.34 \%)$ & $3(100 \%)$ \\
\hline Colistin (10 mcg/disc) & $6(60 \%)$ & $10(55.56 \%)$ & $16(72.72 \%)$ & $3(25 \%)$ & $1(50 \%)$ & - & - \\
\hline Ceftriaxone (30 mcg/disc) & - & $6(33.34 \%)$ & - & $3(25 \%)$ & $1(50 \%)$ & $8(66.67 \%)$ & $2(66.6 \%)$ \\
\hline Ertapenem (10 mcg/disc) & - & $13(72.22 \%)$ & - & $9(75 \%)$ & $2(100 \%)$ & - & $2(66.6 \%)$ \\
\hline Doripenem (10 mcg/disc) & - & - & $10(45.45 \%)$ & $1(8.34 \%)$ & - & - & - \\
\hline Ticarcillin- Clavulanic acid (100 + $10 \mathrm{mcg}$ ) & - & - & $8(36.36 \%)$ & - & - & - & $1(33.3 \%)$ \\
\hline
\end{tabular}

Table 6: Antibiotic resistance pattern of gram positive organisms

\begin{tabular}{|c|c|c|c|}
\hline Antibiotics & $\begin{array}{l}\text { Enterococcus spp } \\
\qquad(n=13)\end{array}$ & $\begin{array}{l}\text { Coagulase negative S.aureus } \\
\qquad(n=15)\end{array}$ & $\begin{array}{c}\text { Staphylococcus aureus } \\
(n=15)\end{array}$ \\
\hline Benzyl Penicillin (10 units/disc) & $1(7.69 \%)$ & $13(86.6 \%)$ & 12 (80\%) \\
\hline Penicillin (10 units/disc) & - & $1(6.67 \%)$ & $1(6.67 \%)$ \\
\hline Gentamicin (120 mcg/disc) & $1(7.69 \%)$ & $6(40 \%)$ & $2(13.3 \%)$ \\
\hline Ciprofloxacin (5 mcg/disc) & $5(38.46 \%)$ & $10(66.6 \%)$ & $10(66.6 \%)$ \\
\hline Levofloxacin (5 mcg/disc) & $3(23.07 \%)$ & $8(53.3 \%)$ & - \\
\hline Erythromycin (15 mcg/disc) & $3(23.07 \%)$ & $9(60 \%)$ & $9(60 \%)$ \\
\hline Clindamycin (2 mcg/disc) & $3(23.07 \%)$ & $9(60 \%)$ & $5(33.3 \%)$ \\
\hline Teicoplanin (30 mcg/disc) & - & $2(13.3 \%)$ & $1(6.6 \%)$ \\
\hline Linezolid (30 mcg/disc) & - & $2(13.3 \%)$ & $2(13.3 \%)$ \\
\hline Tigecycline (15 mcg/disc) & - & $1(6.6 \%)$ & - \\
\hline Vancomycin (30 mcg/disc) & - & $3(20 \%)$ & $1(6.6 \%)$ \\
\hline Tetracycline (30 mcg/disc) & $7(53.8 \%)$ & $3(20 \%)$ & $1(6.6 \%)$ \\
\hline Trimethoprim-Sulfamethoxazole (25 mcg/disc) & - & $2(13.3 \%)$ & $3(20 \%)$ \\
\hline Piperacillin-Tazobactum (100 + 10 mcg) & $1(7.69 \%)$ & - & - \\
\hline Cefuroxime (30 mcg/disc) & $1(7.69 \%)$ & - & - \\
\hline Cefuroxime axetil (30 mcg/disc) & $1(7.69 \%)$ & - & - \\
\hline Cefoperazone-sulbactam (75+30 mcg) & $2(15.38 \%)$ & - & - \\
\hline Cefepime (30 mcg/disc) & $1(7.69 \%)$ & - & - \\
\hline Ceftriaxone (30 mcg/disc) & $2(15.38 \%)$ & $1(6.67 \%)$ & - \\
\hline
\end{tabular}

\section{DISCUSSION}

Diabetic foot ulcer is an important complication of DM. Untreated diabetic foot ulcers will become infected leading to various other consequences such as gangrene or amputation of the limb. Surgical intervention and treatment with antibiotic regimen are the options used for the management of DFUs. ${ }^{[5]}$ The study was carried out to determine the predominant organisms isolated from DFUs and evaluate their sensitivity pattern to different antimicrobials which are vital for prescribing appropriate antibiotic regimen.
In the present study, male predominance was noted over females. Previous studies have shown that the susceptibility to foot infections is greater in male patients than in female patients. ${ }^{[6,7]}$ This may be due to the fact that males tend to be more active in the outdoor activities leading to injuries and prone to development of ulcers. In the current study, we found that elderly patients with age range 60-69 years constituted the majority with foot infections. The mean age of patients in the present study is $58.78 \pm 10.09$ years which is on the line of study by Sundresh NJ et al. ${ }^{[8]}$ and Halpati 
Table 7: Antibiotic resistance pattern of gram-negative organisms

\begin{tabular}{|c|c|c|c|c|c|c|c|}
\hline Antibiotics & $\begin{array}{l}\text { A.baumanni } \\
(n=10)\end{array}$ & $\begin{array}{c}\text { Klebsiella } \\
\text { Species }(n=18)\end{array}$ & $\begin{array}{l}\text { P.aeruginosa } \\
\quad(n=22)\end{array}$ & $\begin{array}{c}\text { E.coli } \\
(n=12)\end{array}$ & $\begin{array}{l}\text { C.koseri } \\
(n=2)\end{array}$ & $\begin{array}{l}\text { Proteus spp } \\
(n=12)\end{array}$ & $\begin{array}{l}\text { Morganella spp } \\
\quad(n=3)\end{array}$ \\
\hline Gentamicin (120 mcg/disc) & $3(30 \%)$ & $3(16.6 \%)$ & $9(41 \%)$ & $1(8.3 \%)$ & - & $3(25 \%)$ & - \\
\hline Ciprofloxacin (5 mcg/disc) & $3(30 \%)$ & $6(33.3 \%)$ & $10(45.45 \%)$ & $5(41.6 \%)$ & $1(50 \%)$ & $5(41.6 \%)$ & - \\
\hline Levofloxacin (5 mcg/disc) & $1(10 \%)$ & - & $10(45.45 \%)$ & - & - & $1(8.3 \%)$ & - \\
\hline Tigecycline (15 mcg/disc) & $1(10 \%)$ & - & $11(50 \%)$ & - & - & 4 (33.3\%) & $1(33.3 \%)$ \\
\hline $\begin{array}{l}\text { Trimethoprim/Sulfamethoxazole } \\
\text { (25 mcg/disc) }\end{array}$ & $1(10 \%)$ & $9(50 \%)$ & $11(50 \%)$ & $2(16.6 \%)$ & $1(50 \%)$ & $4(33.3 \%)$ & - \\
\hline Ampicillin (10 mcg/disc) & $3(30 \%)$ & $15(83.3 \%)$ & $1(4.6 \%)$ & $10(83.34 \%)$ & - & $5(41.67 \%)$ & $2(66.6 \%)$ \\
\hline $\begin{array}{l}\text { Amoxicillin-Clavulanic acid } \\
(30 \mathrm{mcg} / \mathrm{disc})\end{array}$ & $3(30 \%)$ & 7 (38.9\%) & $1(4.6 \%)$ & $2(16.6 \%)$ & $1(50 \%)$ & $1(8.3 \%)$ & $2(66.6 \%)$ \\
\hline Piperacillin-Tazobactum (100 + 10 mcg) & $4(40 \%)$ & $6(33.3 \%)$ & $11(50 \%)$ & $1(8.3 \%)$ & - & $1(8.3 \%)$ & - \\
\hline Cefuroxime (30 mcg/disc) & $3(30 \%)$ & $11(61.72 \%)$ & $1(4.6 \%)$ & $8(66.6 \%)$ & $2(100 \%)$ & $2(16.6 \%)$ & $2(66.6 \%)$ \\
\hline Cefuroxime axetil (30 mcg/disc) & $3(30 \%)$ & $11(61.72 \%)$ & $1(4.6 \%)$ & $8(66.6 \%)$ & 2 (100\%) & $2(16.6 \%)$ & $2(66.6 \%)$ \\
\hline $\begin{array}{l}\text { Cefoperazone-sulbactam } \\
(75+30 \mathrm{mcg} / \text { disc })\end{array}$ & $2(20 \%)$ & $5(27.8 \%)$ & $9(41 \%)$ & $1(8.3 \%)$ & - & $1(8.3 \%)$ & - \\
\hline Cefepime (30 mcg/disc) & $4(40 \%)$ & $6(33.3 \%)$ & $6(50 \%)$ & $2(16.6 \%)$ & - & $2(16.6 \%)$ & - \\
\hline Imipenem (10 mcg/disc) & $3(30 \%)$ & $3(16.67 \%)$ & $3(13.7 \%)$ & $1(8.3 \%)$ & - & - & - \\
\hline Meropenem (10 mcg/disc) & $3(30 \%)$ & $3(16.67 \%)$ & $4(18.18 \%)$ & $1(8.3 \%)$ & - & $1(8.3 \%)$ & - \\
\hline
\end{tabular}

A et al. ${ }^{[9]}$ which showed an incidence of 58.3 years and 59.5 years, respectively.

Among the co-morbidities, hypertension was the most prevalent co-morbidity seen among the study population followed by peripheral vascular occlusive disease, kidney diseases, ischemic heart disease, and blood disorders. These findings are consistent with the earlier published literatures. ${ }^{[10,11]}$ It is well known that hypertension is a common co-morbidity in patients with DM with a prevalence of up to two-thirds of the population and it may be present by the time patients are diagnosed to have DM or even before the onset of hyperglycemia. Hypertension enhances the risk for cardiovascular diseases in patients with DM by increasing the risk of developing microvascular and macrovascular complications.

Our study revealed that 43 out of 71 patients developed ulcers with size less than or equal to $4 \mathrm{~cm}^{2}$ and showed recovered quickly while 28 subjects had ulcers of size greater than $4 \mathrm{~cm}^{[2]}$ where recovery was slower compared to patients with smaller ulcer size. A study carried out by Oyibo et al. ${ }^{[12]}$ showed that greater the area of the ulcer more would be the healing time.

The current study categorized the ulcers into necrotic (36.61\%) and non-necrotic $(63.38 \%)$ where the frequency of subjects who presented with non-necrotic ulcers was higher. Previous studies have shown that there is an association between bacterial growth and severity pattern of ulcers. ${ }^{[13]}$ In our study, monomicrobial growth $(53.52 \%)$ was predominant than polymicrobial infections $(46.47 \%)$ which could be the reason for the increased prevalence of non-necrotic ulcers. Monomicrobial nature of diabetic foot ulceration has been reported in several studies conducted in this region and elsewhere. ${ }^{[14,15]}$ But few studies from India have reported a higher prevalence of necrotic cases and polymicrobial infections. ${ }^{[16-18]}$

Microbiological evaluation of diabetic foot ulcer infections showed that the prevalence of gram-negative organisms was found to be more than gram-positive organisms. Pseudomonas aerugenosa was the most frequent followed by Klebsiella pneumonia and E.coli. These findings correlated well with those of studies carried out in India which showed that gram-negative bacilli as the most common organism and pseudomonas being the predominant pathogen. ${ }^{[19-21]}$ However, few studies reported gram positive as the most common organism and Staphylococcus aureus as the most common isolate. ${ }^{[22-24]}$ Therefore, there seems to be a changing trend in the organisms causing diabetic foot infections with gram-negative bacteria replacing gram-positive bacteria as commonest agents. It also confirms the fact that the diabetic foot infections do not have a clear etiology.

Knowledge about the antibiotic susceptibility pattern of the isolates is also essential for proper management of diabetic foot infections. Antibiotics such as Vancomycin, Tigecycline, and Linezolid showed $>85 \%$ susceptibility towards gram- positive isolates. In the present study, Staphylococcus species isolated were susceptible to Gentamicin, Tetracycline, Vancomycin, Teicoplannin, and Linezolid. So, these antibiotics seem to be appropriate for empirical treatment of diabetic foot infections. Coagulase negative staphylococcus showed only $73 \%$ susceptibility towards Teicoplannin, Linezolid, and Vancomycin. Most of the gram-positive organism showed low susceptibility to Penicillin, Cephalosporins, and Fluoroquinolones. 
In the present study, Imipenem and Meropenem showed very good susceptibility against Pseudomonas and Klebsiella species. Amikacin showed 100\% susceptibility against E.coli whereas Piperacillin with Tazobactam combination, Gentamicin, Meropenem, Imipenem, and Cefoperaxone with Sulbactam combination showed more than $80 \%$ susceptibility. Proteus species showed $100 \%$ susceptibility to Piperacillin with Tazobactam combination and more than $80 \%$ susceptibility to Cefepime, Amikacin, Meropenem, and Cefoperazone with Sulbactam combination. Acenobacter species showed low susceptibility towards most of the fluoroquinolones, aminoglycosides, cephalosporins, and carbapenams.

Considering the resistance pattern of antibiotics towards the bacterial isolates, in our study, many organisms showed multi-drug resistance towards gram negative and gram-positive organisms. This increased incidence of multi-drug resistant organisms is a potential risk factor in the management of diabetic foot infections which may lead to the occurrence of complications like systemic toxicity, gangrene formation, and amputation of lower extremity. Initiating a combination therapy has been considered as the better option for the successful treatment of diabetic foot infections.

Management of gram-negative infections is extremely challenging. Future studies should also focus on identifying the risk factors for the development of these infections so that appropriate treatment can be initiated early and can prevent or minimize drug resistance and fatal outcomes.

The present study demonstrates that a variety of organisms can be isolated from diabetic foot ulcers. Knowledge about the microbes that cause infection and their susceptibility towards the antibiotics will allow physicians to make best out their choice. Considering the nature of the organism and the type of isolate appropriate empirical antibiotic therapy should be initiated especially for the patients who are at risk categories. Once the nature of the organism and the probable pathogens are isolated, de-escalation of empiric therapy with a single drug or combination therapy can be guided by relevant culture results.

\section{CONCLUSION}

This study showed the predominance of gram-negative organisms over gram-positive organisms with the majority of the infections to be monomicrobial in nature. It is necessary to evaluate the culture sensitivity test from the infected wound and the knowledge on the antibiotic sensitivity pattern of the isolates helps in planning treatment with the appropriate antibiotic regimen. This, in turn, helps to prevent the emergence of drug-resistant organisms and minimizing healthcare costs. Clinical pharmacists can play a vital role in suggesting suitable antibiotic treatment regimen for the proper management of diabetic foot ulcers. They can also be involved in educating the patients about the importance of maintaining optimal glycemic control and avoiding the risk factors for developing ulcers which will help in improving the quality of life.

\section{Financial support and sponsorship}

Nil.

\section{Conflicts of interest}

There are no conflicts of interest.

\section{REFERENCES}

1. Huri HZ. Management of the Diabetic Foot. Continuing Professional Development (CPD: Pharmacy Today (Malaysia). Pharmacy Practice 2014:31-38.

2. Shrivastava SR, Shrivastava PS, Ramasamy J. Role of self-care in management of diabetes mellitus. J Diabetes Metab Disord 2013;12:14.

3. Mendes JJ, Marques-Costa A, Vilela C, Neves J, Candeias N, Cavaco-Silva $\mathrm{P}$, et al. Clinical and bacteriological survey of diabetic foot infections in lisbon. Diabetes Res Clin Pract 2012;95:153-61.

4. Tamali M, Gamal MB, Alghazal MA. Common aerobic bacterial isolates from diabetic foot ulcer and their antibiotic susceptibility testing. World J Pharm Pharm Sci 2015;4:260-66.

5. Perim MC, Borges Jda C, Celeste SR, Orsolin Ede F, Mendes RR, Mendes $\mathrm{GO}$, et al. Aerobic bacterial profile and antibiotic resistance in patients with diabetic foot infections. Rev Soc Bras Med Trop 2015;48:546-54.

6. George A, Dan AA, Eapen BA, Chaithra S, Sivakumar TA. Prospective Study on Bacteriology and Prescribing Pattern of Antibiotics in Diabetic Foot Ulcers at a Tertiary Care Teaching Hospital. WJPMR. 2016;2:128-31

7. Mehta VJ, Kikani KM, Mehta SJ. Microbiological profile of diabetic foot ulcers and its antibiotic susceptibility pattern in a teaching hospital. Int J Basic Clin Pharmacol 2014;3:92-95.

8. Sundresh NJ, Narendran S, Ramesh R, Kesavjagadeesan, Nasarareddy N. Clinical and microbiological study of diabetic foot in patients admitted at RMMCH, Chidambaram,Tamil Nadu, India. J Pharm Sci Innov 2014;3:135-38.

9. Halpati A, Desai KJ, Jadeja R, Parmar M. A study of aerobic and anaerobic bacteria in diabetic foot ulcer and in vitro sensitivity of antimicrobial agent. Int J Med Sci Public Health 2014;3:818-21.

10. Venkateswaramurthy N, Malaravan N, Sambathkumar R. Clinical and Microbial Flora in Diabetic foot ulcer and its Antibiotic sensitivity pattern. Int J Adv Pharm Gen Res 2015;3:1-9.

11. Reghu R, Padma UD, Sasankan V, Puthur S, Jose J. A microbiological study of diabetic foot ulcer in a south Indian tertiary care hospital. Int J Pharm Sci Rev Res 2016;37:167-70.

12. Oyibo SO, Jude EB, Tarawneh I, Nguyen HC, Armstrong DG, Harkless LB, et al. The effects of ulcer size and site, patient's age, sex and type and duration of diabetes on the outcome of diabetic foot ulcers. Diabet Med 2001;18:133-8.

13. Kavitha KV, Tiwari S, Purandare VB, Khedkar S, Bhosale SS, Unnikrishnan AG. Choice of wound care in diabetic foot ulcer: A practical approach. World J Diabetes 2014;5:546-56.

14. Jithendranath A, Hegadi S, Bhai G, Bhargavi L, Bai R, Vishu T. bacteriological profile of diabetic foor in a tertiary care centre in Trivandrum, India. Int J Curr Microbiol App Sci 2016;5:279-86. 
15. Tiwari S, Pratyush DD, Dwivedi A, Gupta SK, Rai M, Singh SK. Microbiological and clinical characteristics of diabetic foot infections in northern india. J Infect Dev Ctries 2012;6:329-32.

16. Sekhar S, Vyas N, Unnikrishnan M, Rodrigues G, Mukhopadhyay C. Antimicrobial susceptibility pattern in diabetic foot ulcer: A pilot study. Ann Med Health Sci Res 2014;4:742-5.

17. Islam S, Cawich SO, Budhooram S, Harnarayan P, Mahabir V, Ramsewak S, et al. Microbial profile of diabetic foot infections in trinidad and tobago. Prim Care Diabetes 2013;7:303-8.

18. Chavan SK, Karande GS, Mohite RV. Clinico-bacteriological profile of diabetic foot ulcer among patients attending rural tertiary health care centre. Int J Med Res Health Sci 2014;3:861-85.

19. Manisha J, Mitesh P, Nidhi S, Dhara M, Vegad M. Spectrum of microbial flora in diabetic foot ulcer and its antibiotic sensitivity pattern in tertiary care hospital in Ahmedabad, Gujarat. N J Med Res 2012;2:354-57.
20. Shanmugam P, M J, Susan S L. The bacteriology of diabetic foot ulcers, with a special reference to multidrug resistant strains. J Clin Diagn Res 2013;7:441-5

21. Iyanar K, Premavathy R, Sambandam C, Jayalakshmi M, Sruthi P, Shantha S. Isolation and antibiotic susceptibility of bacteria from foot infections in the patients with diabetes mellitus type 1 and type 2 in the district of Kancheepuram, Tanil Nadu, India. Int J Res Med Sci 2014;2:457-61.

22. Sugandhi P, Prasanth DA. Microbiological profile of bacterial pathogens from diabetic foot infections in tertiary care hospitals, salem. Diabetes Metab Syndr 2014;8:129-32.

23. Al Benwan K, Al Mulla A, Rotimi VO. A Study of the microbiology of diabetic foot infections in a teaching hospital in kuwait. J Infect Public Health 2012;5:1-8.

24. Banu A, Noorul Hassan MM, Rajkumar J, Srinivasa S. Spectrum of bacteria associated with diabetic foot ulcer and biofilm formation: A prospective study. Australas Med J 2015;8:280-5. 